\title{
Invasive Nile tilapia dominates a threatened indigenous tilapia in competition over shelter
}

\author{
T. Champneys $(\mathbb{D} \cdot$ M. J. Genner · C. C. Ioannou
}

Received: 26 April 2020/Revised: 16 June 2020/Accepted: 20 June 2020/Published online: 11 August 2020

(C) The Author(s) 2020

\begin{abstract}
Invasive species are one of the greatest threats to freshwater ecosystems globally. However, the causal mechanisms that drive negative impacts of many invasive species are poorly understood. In Tanzania, non-native Nile tilapia (Oreochromis niloticus) exists in sympatry with a diverse range of native species, many of which are congenerics with strong niche overlap. It has been suggested that $O$. niloticus can displace native species from preferred habitat through dominance during interference competition, yet interference competition between $O$. niloticus and a native tilapia species has never been directly tested under experimental conditions. In this study juvenile O. niloticus and Manyara tilapia (Oreochromis amphimelas), a functionally similar but endangered Tanzanian cichlid, were size matched in conspecific and heterospecific pairs. We presented pairs with limited shelter and recorded competitive interactions.
\end{abstract}

Guest editors: S. Koblmüller, R. C. Albertson, M. J. Genner, K. M. Sefc \& T. Takahashi / Advances in Cichlid Research IV: Behavior, Ecology and Evolutionary Biology

Electronic supplementary material The online version of this article (https://doi.org/10.1007/s10750-020-04341-8) contains supplementary material, which is available to authorized users.

T. Champneys $(\varangle) \cdot$ M. J. Genner · C. C. Ioannou School of Biological Sciences, University of Bristol, Life Sciences Building, 24 Tyndall Avenue, Bristol, UK e-mail: toby.champneys@bristol.ac.uk
We found that $O$. niloticus were more aggressive and faster to initiate agonistic interactions than $O$. amphimelas. Furthermore, O. niloticus showed a strong competitive dominance in their interactions with $O$. amphimelas. One-sided dominance hierarchies can drive fundamental changes in resource use by subordinate individuals, potentially resulting in habitat displacement over the long term. Based on this experimental evidence, we conclude that $O$. niloticus may threaten native tilapia species through dominance in interference competition.

Keywords Aggression - Agonistic interaction · Aquaculture · Competitive exclusion · Dominance index $\cdot$ Interspecific competition

\section{Introduction}

Invasive species pose a major threat to aquatic ecosystems and can cause biodiversity loss, species extinction and adverse socioeconomic changes (Kaufman, 1992; Pringle, 2005). Underlying these impacts are causal mechanisms that explain why an invasive species has a given effect in an ecosystem. These mechanisms can operate from the genetic level (i.e. through hybridization; Moralee et al., 2000) to the ecosystem level (i.e. through eutrophication; Starling et al., 2002). An understanding of these mechanisms is 
crucial to develop management strategies to mitigate the effects of current invasions (Vander Zanden et al., 2004), design predictive risk models which may inform policies that prevent future invasions (Kulhanek et al., 2011), and allocate limited resources to efficiently target the most harmful invasive species (Parker et al., 1999). Despite the importance of biological invasions, the poor understanding of mechanisms driving the impacts of many invasive species greatly reduces our ability to tackle the threat of aquatic invasive species (Parker et al., 1999; Kulhanek et al., 2011).

Nile tilapia, Oreochromis niloticus (Linnaeus, 1758), is a freshwater fish in the family Cichlidae, native to Western Africa and the Nile basin (Trewavas, 1983). It now has a pan-tropical non-native distribution (Canonico et al., 2005), with the spread largely due to its role in aquaculture. It is estimated that $98 \%$ of $O$. niloticus production occurs outside its native range, and accidental releases are frequent (Naylor et al., 2001; Shelton, 2002). O. niloticus gained popularity as an aquaculture species due to its broad environmental tolerance, fast growth rate and high fecundity (Zale \& Gregory, 1989; Avella et al., 1993). These characteristics are favourable in aquaculture, but give the species high invasive potential. Successful establishment of non-native populations has taken place in the majority of countries where culture has been initiated (Ehrlich, 1989; CostaPierce, 2003).

Given the widespread distribution of $O$. niloticus, research into its effect on ecosystems outside of their native range is growing (Canonico et al., 2005). A number of studies have demonstrated declines in populations of native fish following the establishment of $O$. niloticus, with examples from mainland Africa (Van der Waal \& Bills, 2000; Balirwa et al., 2003), Madagascar (Lévêque, 1997), Brazil (Starling et al., 2002), Nicaragua (McCrary et al., 2001), and China (Gu et al., 2015). However, despite the potential threat posed by invasive $O$. niloticus, the mechanisms driving such declines remain poorly understood, and the need for further research into these mechanisms has been highlighted (Canonico et al., 2005; Bradbeer et al., 2019).

It has been proposed that $O$. niloticus can aggressively displace native species from their preferred habitat through dominance in interference competition (Goudswaard et al., 2002). This has been demonstrated under laboratory conditions, where $O$. niloticus decreased the shelter use of the native sunfish species Lepomis miniatus (Jordan, 1877) and increased the risk of sunfish mortality from predation (Martin et al., et al., 2010). A similar experiment demonstrated that $O$. niloticus dominates competitive interactions with the native Brazilian pearl cichlid Geophagus brasiliensis (Quoy \& Gaimard, 1824), even when competing with larger pearl cichlid individuals (Sanches et al., 2012). Such studies clearly demonstrate the aggressive phenotype of O. niloticus, its tendency to dominate other species in competitive interactions, and the harmful impacts that can result from such interactions. However, given the extensive non-native range of $O$. niloticus, and the diversity of species it encounters, more work is needed to explore the ubiquity of this mechanism. This is especially important in light of the ecological consequences that can result from competitive dominance by invasive species (Case et al., 1994). Hence, examining how more species interact with $O$. niloticus could lend novel insights into the wider impacts of this species.

In Tanzania, non-native $O$. niloticus populations are now well established (Ogutu-Ohwayo, 1990; Njiru et al., 2004), and yet interference competition between $O$. niloticus and native Tanzanian fish species has never been directly tested. Unlike the studies of interactions between $O$. niloticus and species native to the Americas, Tanzania is home to a number of native congeneric tilapia species which are both closely related and functionally similar to $O$. niloticus (Zengeya et al., 2015), and it is not clear whether these species can be outcompeted by $O$. niloticus. Interference competition is speculated to have driven the declines of native tilapia species in Lake Victoria (Goudswaard et al., 2002), but direct evidence supporting this is lacking. Furthermore, it has been proposed that $O$. niloticus was responsible for the local extinction of the native tilapia species Oreochromis urolepis (Norman, 1922) from Lake Hombolo, Tanzania (Turner et al., 2019). These studies that implicate $O$. niloticus as the causal agent in the eradication of a native fish populations highlight the potential vulnerability of functionally similar tilapia species to $O$. niloticus invasion, and consequently interactions between $O$. niloticus and closely related species warrant investigation.

The freshwater habitats of Tanzania are home to an unprecedented biodiversity of fish species and provide 
a valuable system for the study of evolution and social behaviour (Turner, 2007). Tanzanian fish stocks are a crucial source of food and income for a growing human population and are maximally exploited in many cases (FAO, 2018). As a result, investigations into the impacts of introduced $O$. niloticus are especially important in Tanzania, where further ecological damage from invasive species could have negative consequences for local biodiversity and socioeconomic systems. This study focuses on interactions between $O$. niloticus and a functionally similar native Tanzanian cichlid, the Manyara tilapia Oreochromis amphimelas (Hilgendorf, 1905). $O$. amphimelas is endemic to Tanzania and is found in sympatry with non-native $O$. niloticus in lakes Manyara, Sulungali, Eyasi, Singidani and Kitangiri (Shechonge et al., 2019). Currently O. amphimelas is classified as Endangered by the IUCN due to threats from overharvesting, pollution and climate change (Bayona, 2006), and therefore this species is vulnerable to further ecological stressors such as invasive species. Like $O$. niloticus, O. amphimelas are maternal mouthbrooders and are largely microphagous, suggesting strong resource overlap between these species (Trewavas \& Fryer, 1965). Littoral vegetation plays an important role in the life cycle of many tilapia species, particularly for juveniles where it provides shelter from predators (Donnelly, 1969). Therefore competitive interactions over shared resources appear likely, and displacement from preferred habitat could affect individual and population fitness.

Direct evidence of interference competition over habitats between $O$. niloticus and $O$. amphimelas has not yet been demonstrated in situ, and field survey data are necessary to quantify space use and interactions. Nevertheless, it is important to understand the potential for behavioural mechanisms to influence resource use patterns in the species. Therefore, the aim of this study is to conduct the first direct test of interference competition between $O$. niloticus and a closely related native fish species. Under laboratory conditions $O$. niloticus and $O$. amphimelas were size matched in conspecific and heterospecific pairs. Fish were presented with limited shelter resources and we recorded all competitive interactions in two experiments, one containing a single shared shelter and the other containing two separated shelters. The two experiments enabled us to determine how competitive interactions between $O$. niloticus and $O$. amphimelas vary with resource distribution, a known regulator of invasive species impacts.

\section{Methods}

Ethical note

The experimental procedures and housing conditions used in this study were in accordance with the ethical standards of the University of Bristol and ethical approval was granted by the University's Animal Welfare and Ethical Review Body (UIN number: UB 18 067). All fish remained in the laboratory for future use following this experiment.

\section{Subjects and housing}

Non-native populations of $O$. niloticus typically originate from intentional stocking events or escapees from commercial aquaculture (Canonico et al., 2005). Thus, we compared behaviour of $O$. niloticus descended from commercial stock, with wild-type $\left(1^{\text {st }}\right.$ generation from wild) $O$. amphimelas. The $O$. niloticus subjects were purchased from Fish Farm UK (London, UK) and the $O$. amphimelas subjects were provided by Bangor University. Subjects from both species were raised in recirculating aquaculture facilities prior to receipt. Precise ages and parentages were not known when received. However, individuals from both species came from numerous spawning pairs, and at the time of the experiment, were smaller than the size threshold typical for mature individuals (Al Hafedh et al., 1999; Froese \& Pauly, 2019). All fish were housed in a recirculating aquarium at the University of Bristol for four weeks prior to testing. Housing tanks were $190 \mathrm{~L}$, with $O$. amphimelas and $O$. niloticus each housed in two separate tanks. By pairing fish from different tanks, even in the same species tests, we maximised unfamiliarity between individuals. This removed any effect of social hierarchy established during the 4 weeks before testing began. Housing tanks were separated by perforated dividers, preventing movement of individuals between tanks, while allowing olfactory cue transmission. All housing tanks were held at similar densities, 55-65 individuals per tank, because housing density can affect aggression and boldness in tilapia (Champneys et al., 2018). Lighting was maintained on a 12:12 h 
light:dark cycle to mimic natural conditions in the tropics. Fish were fed daily with a mixture of ZM Large Premium Granular feed (Tecniplast, London, UK), TetraMin flake (Tetra, Melle, Germany), frozen bloodworm (CC Moore \& Co, Templecombe, UK) and Gamma ${ }^{\mathrm{TM}}$ Krill Pacifica, chopped prawn, Mysis Shrimp, Brine Shrimp, and Vegetable Diet (Tropical Marine Centre, Chorleywood, UK).

\section{Experimental setup}

Four 36 litre experimental tanks (tank dimensions: 45 $\times 32 \times 25$ cm length $\times$ width $\times$ height) were filled each day to a depth of $14 \mathrm{~cm}$ with 201 of water from the housing tanks (temperature range $24^{\circ}$ to $26^{\circ} \mathrm{C}$ ). The water temperature of the experimental tanks was measured before each individual trial so that any change throughout the day could be accounted for in the statistical analysis. Shelters consisted of artificial plastic vegetation fixed to a plastic board, which was covered with the white aquatic gravel (Pettex Ltd, Ilford, UK) that also lined the bottom of the experimental tanks. Eight stems, each consisting of 14 14-19 $\mathrm{cm}$ long green leaves, were attached to each board, providing a stem density of 160 per $\mathrm{m}^{2}$. This stem density is in line with high density areas of Phragmites (Uddin \& Robinson, 2017), an emergent macrophyte found in Tanzanian freshwater systems. Identical shelters were also placed in each of the housing tanks to remove novelty and to encourage individuals to associate the structure with shelter. To prevent disturbance during experiments, experimental tanks were visually isolated from each other with opaque plastic boards, and the surrounding room with opaque plastic sheet hanging from a metal frame.

In experiment one, tanks were divided into three zones of equal size $(15 \times 32 \mathrm{~cm})$, one consisting entirely of shelter and the other two of bare substrate, with the area of bare substrate divided into two by a removable door (Fig. 1a). In experiment two, tanks were also divided into three zones of equal size $(15 \times$ $32 \mathrm{~cm})$ : two half-shelter sections consisting of a smaller shelter $(15 \times 16 \mathrm{~cm})$ and half substrate $(15 \times$ $16 \mathrm{~cm}$ ), and a third section of bare substrate between them. The shelters within the half-shelter sections were positioned in opposing corners and a removable door separated one half-shelter section from the other two thirds of the tank (Fig. 1b). Therefore, overall habitat cover and complexity was the same in both experiments. However, we hypothesised that the spatial separation of the shelter could mitigate aggression between the species and provide insights into potential conservation measures.

\section{Experimental protocol}

Experiment one (Fig. 1a) consisted of an 'occupant' which was acclimated within the two thirds of the tank containing bare substrate and the shelter, and an 'intruder' which was acclimated behind an opaque removable door in the third of the tank containing bare substrate. To test how $O$. niloticus and $O$. amphimelas interact over a single shelter resource, three treatments were used: (1) $O$. amphimelas occupant and $O$. amphimelas intruder ( $n=19$ trials), (2) O. niloticus occupant and O. niloticus intruder $(n=18)$, and (3) $O$. amphimelas occupant and $O$. niloticus intruder $(n=$ 16). Due to a limited sample size of $O$. amphimelas subjects, a fourth treatment consisting of an $O$. niloticus occupant and an $O$. amphimelas intruder was not included in either experiments. Thus, our experiment simulates the introduction of $O$. niloticus individuals where $O$. amphimelas is already a resident species. Experiment one was conducted between the 14th and 19th January 2019.

Experiment two (Fig. 1b) consisted of an 'occupant' which was acclimated within two thirds of the tank containing a bare substrate and a half-shelter section, and an 'intruder' which was acclimated behind an opaque removable door in the other third of the tank containing a half-shelter section. To test how $O$. niloticus and O. amphimelas interact over two, spatially divided shelter resources, the same three treatments were used as in experiment one: (1) $O$. amphimelas occupant and $O$. amphimelas intruder $(n=$ 13 trials), (2) O. niloticus occupant and O. niloticus intruder ( $n=18)$, and (3) O. amphimelas occupant and $O$. niloticus intruder $(n=19)$. Experiment two was conducted between 12th and 19th February 2019 using the same fish as experiment one, meaning that some pairs may have been recombined. No fish was used more than once in each experiment.

Differences in sample size between treatments resulted from discarded trials, where the intruder escaped under the removable door during acclimatisation, or the camera recording failed. Additionally, in experiment two, sample sizes for the O. amphimelasO. amphimelas treatment were reduced compared to 


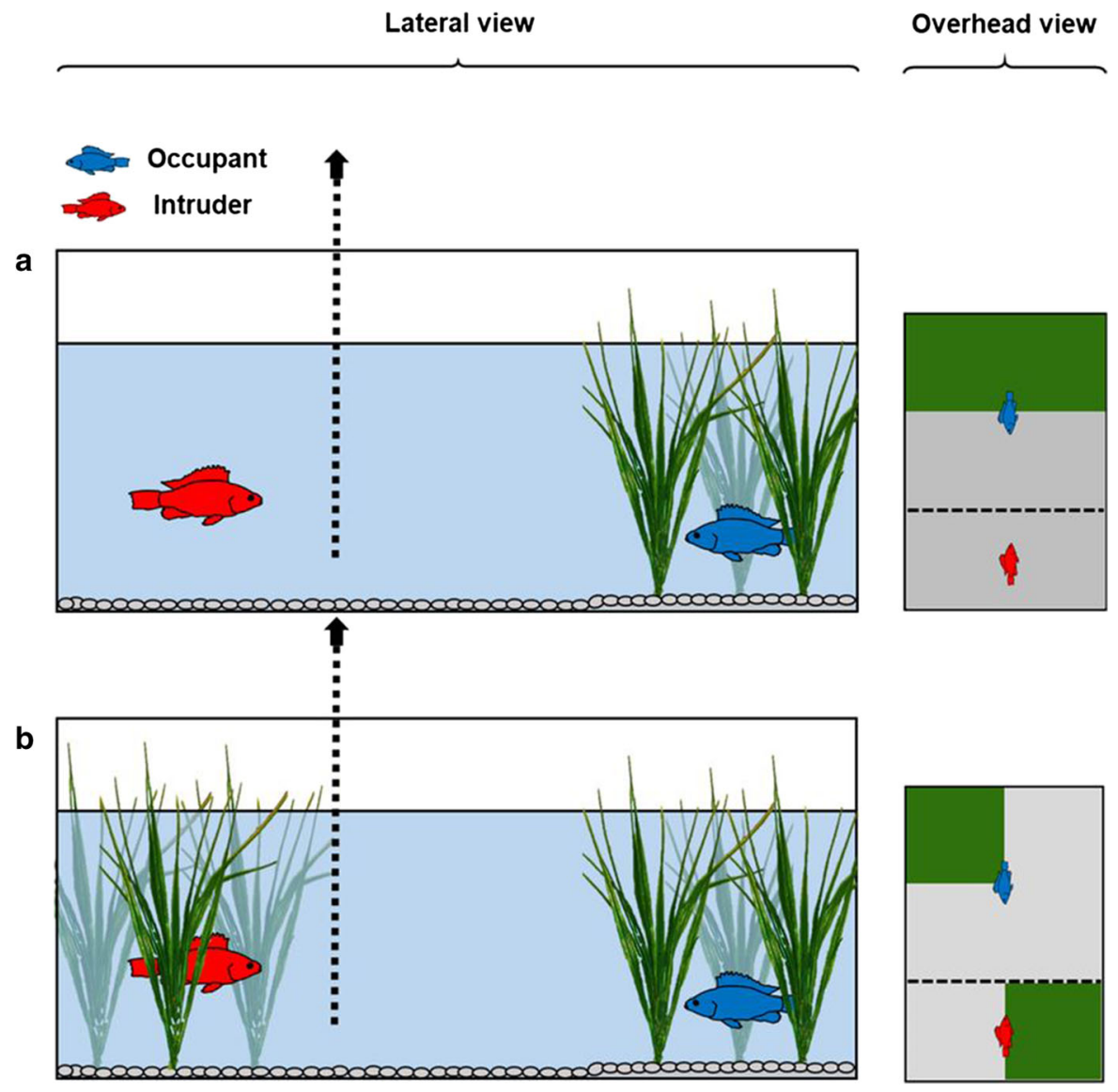

Fig. 1 Lateral and overhead view of experimental tank setup for $\mathbf{a}$ experiment one and $\mathbf{b}$ experiment two (not to scale). In both views, dashed lines represent the opaque removable door, green

experiment one because growth rates varied between individuals within the population over the 24 days between experiments one and two, preventing size matching of all available experimental fish.

At the start of each trial, an occupant and an intruder were netted haphazardly from their respective housing tanks and size matched by measuring total length (TL) with callipers. If the absolute size difference exceeded $10 \mathrm{~mm}$, the intruder was returned, and a different individual was netted (Table 1).

In both experiments, four experimental setups were run simultaneously, with one of each treatment and an additional trial of a randomly selected treatment. Treatments were randomly assigned to one of the four experimental tanks. Occupant individuals were placed in the larger section of the tank containing a bare sediment and a shelter section in experiment one and a bare sediment and half-shelter section in experiment areas represent shelter and grey areas represent bare sediment. Red fish represent intruders and blue fish represent occupants

two. Intruders were placed behind the opaque removable door in the remaining third of the tank, which contained a bare sediment section in experiment one and a mixed section in experiment two (Fig. 1). The trial began with a 30-min acclimation period. Both species initiate feeding in this time in a similar experimental setup (unpublished data). Following acclimation, the door was raised by hand, while the rest of the experimenter was obscured from view, and the fish were able to explore the tank and interact for $15 \mathrm{~min}$.

Recording and video analysis

In both experiments, the 15-min interaction period was recorded on two overhead GoPro Hero 6 cameras (linear field of view, 30 frames/s, $1280 \times 720$, GoPro Inc., San Mateo, CA, USA), each recording two of the 
four tanks. Video recordings were analysed using BORIS version 7.4.6, by one reviewer to ensure consistency (Friard \& Gamba, 2016). The time spent outside of shelter by the occupant was recorded, along with all agonistic interactions between the occupant and the intruder. Being out of shelter was defined as when more than half of the individual's body length was both past the edge of the plastic board at the base of the shelter and less than half covered by a leaf from one of the stems. The agonistic interactions recorded were biting, chasing, and mouth fighting, and were defined according to a published ethogram on $O$. niloticus (Alvarenga \& Volpato, 1995). The behaviour definitions are as follows: biting (termed nipping by Alvarenga \& Volpato, 1995, but renamed to avoid confusion with non-aggressive interactions) "the aggressor swims towards the opponent and bites", chasing "the aggressor swims towards the opponent, while the opponent swims away from the aggressor, without any physical contact", mouth fighting "both fish approach frontally with the mouth open and bite the opponent's mouth" (Alvarenga \& Volpato, 1995). A number of behaviours associated with aggression in cichlids such as gill spreads, tail beats and lateral displays were not recorded in this experiment as they were hard to definitively identify with the overhead camera setup. These behaviours carry a low injury risk while providing an assessment of fighting ability (Enquist et al., 1990). Physical displays of aggression are thought to be a highly escalated form of competitive interaction in cichlids (Enquist et al., 1990), and these are the focus of our analysis.

The initiator (occupant or intruder) was recorded for each interaction. This information was used to calculate the time taken for the two fish to first interact and the number of agonistic interactions. The number of agonistic interactions was also used to analyse the level of competitive dominance shown by occupants. Based on our definition of chasing, the aggressor always forced the other fish to swim away (Alvarenga $\&$ Volpato, 1995). Biting typically resulted in a similar avoidance response from the recipient, but when retaliation occurred, this was recorded as a separate event. Typically, the losers of competitive interactions in cichlid fish are defined by an avoidance response and/or a lack of retaliation (Oliveira et al., 2004; Reddon \& Hurd, 2009) following an agonistic interaction. We were therefore confident that the number of agonistic interactions initiated by the occupant relative to the intruder could act as a measure of dominance in our analysis. This is similar to methods outlined in Bailey et al. (2000) and Sanches et al. (2012) who defined dominance by the proportion of agonistic interactions initiated by an individual. The definition of mouth fighting outlined by Alvarenga \& Volpato (1995) states that "both fish approach frontally" meaning that an initiator cannot be clearly identified. As a result, mouth fighting was recorded as an agonistic interaction directed by both individuals. This meant that it did not affect the number of interactions directed by the occupant relative to the intruder (dominance), while still providing information on the total number of agonistic interactions occurring in each treatment.

\section{Statistical analysis}

All analyses were conducted using $\mathrm{R}$ version 3.6.0 ( $\mathrm{R}$ Core Team, 2019). The time taken for the first interaction between occupant and intruder was analysed in both experiments with a Cox Proportional Hazards Model using the 'coxph' function in the package 'survival' (Therneau, 2015). This analyses how the probability of an event occurring is affected by a given set of risk factors at any given time. Here, the event was the first interaction between occupant and intruder, the risk factors are the model covariates: treatment, temperature and intruder length (TL), and the time is the experiments' duration (900 s; Table 2). Survival analysis allows both the time taken for the first interaction to occur and whether or not an interaction did occur within the $900 \mathrm{~s}$ to be included. The effect of each covariate on the probability of a first interaction is calculated while taking all other covariates into account. A hazard is the likelihood of the event occurring at a specific time, and in a Cox Proportional Hazards Model, hazards are assumed to be consistent over time. In the data from experiment one, an initial test using the cox.zph function revealed a violation of this proportional hazard assumption through significant test results for the intruder length (TL) covariate $(P<0.001)$ and the global test $(P=$ 0.004). In experiment two, a significant test result was also found for the intruder length (TL) covariate $(P=$ $0.04)$, while the global test was non-significant $(P=$ $0.1)$. Plotting residuals over time revealed intruder length (TL) to have a time varying effect for both experiments, so time was stratified into three separate 
Table 1 Mean total length \pm SD (mm) of occupants and intruders for each treatment in experiments one and two

\begin{tabular}{|c|c|c|c|c|}
\hline Experiment & Trial type & $\begin{array}{l}\text { Mean total length of } \\
\text { occupants } \pm \mathrm{SD}(\mathrm{mm})\end{array}$ & $\begin{array}{l}\text { Mean total length of } \\
\text { intruders } \pm \mathrm{SD}(\mathrm{mm})\end{array}$ & $\begin{array}{l}\text { Mean per trial size difference (occupant } \\
\text { length - intruder length) } \pm \mathrm{SD}(\mathrm{mm})\end{array}$ \\
\hline One & $\begin{array}{l}\text { O. amphimelas - } \\
\text { O. amphimelas }\end{array}$ & $58.9 \pm 3.88$ & $58.74 \pm 4.07$ & $0.16 \pm 2.05$ \\
\hline One & $\begin{array}{l}O . \text { niloticus }-O \text {. } \\
\text { niloticus }\end{array}$ & $55.69 \pm 3.59$ & $56.34 \pm 3.81$ & $-0.65 \pm 1.94$ \\
\hline One & $\begin{array}{l}\text { O. amphimelas- } \\
\text { O. niloticus }\end{array}$ & $59.43 \pm 5.73$ & $58.3 \pm 5.51$ & $1.13+2.09$ \\
\hline Two & $\begin{array}{l}\text { O. amphimelas- } \\
\text { O. amphimelas }\end{array}$ & $59.06 \pm 4.62$ & $59.05 \pm 4.01$ & $0.02 \pm 3.02$ \\
\hline Two & $\begin{array}{l}O . \text { niloticus }-O \text {. } \\
\text { niloticus }\end{array}$ & $67.41 \pm 5.58$ & $67.39 \pm 5.03$ & $0.01 \pm 1.77$ \\
\hline Two & $\begin{array}{l}\text { O. amphimelas- } \\
\text { O. niloticus }\end{array}$ & $63.11 \pm 3.96$ & $63.15 \pm 4.38$ & $-0.05 \pm 1.21$ \\
\hline
\end{tabular}

The mean size difference of occupants compared to intruders \pm SD $(\%)$ in each trial is also shown

Table 2 Definitions and range/levels of the five explanatory variables used across analyses

\begin{tabular}{|c|c|c|}
\hline $\begin{array}{l}\text { Explanatory } \\
\text { variable }\end{array}$ & Definition & range/levels \\
\hline Treatment & Species & $\begin{array}{l}\text { "O. amphimelas-O. amphimelas" "O. niloticus-O. } \\
\text { niloticus", "O. amphimelas-O. niloticus" }\end{array}$ \\
\hline Role & Role of the individual & "Occupant", "Intruder" \\
\hline Size difference & $\begin{array}{l}\text { Percentage total length difference between } \\
\text { occupant and intruder }\end{array}$ & $\begin{array}{l}\text { Experiment one: }-7.88 \text { to }+7.33(\%) \text {, experiment two: }- \\
9.66 \text { to }+8.61(\%)\end{array}$ \\
\hline $\begin{array}{l}\text { Absolute size } \\
\text { difference }\end{array}$ & $\begin{array}{l}\text { Absolute percentage total length difference } \\
\text { between occupant and intruder }\end{array}$ & Experiment one: 0 to $7.88(\%)$, experiment two: 0 to $9.66(\%)$ \\
\hline Intruder length & Total length of the intruder & $\begin{array}{l}\text { Experiment one: } 49 \text { to } 66.33(\mathrm{~mm}) \text {, experiment two: } 51 \text { to } \\
74.9(\mathrm{~mm})\end{array}$ \\
\hline Temp & Temperature of the experimental tank water & $\begin{array}{l}\text { Experiment one: } 24 \text { to } 26\left({ }^{\circ} \mathrm{C}\right) \text {, experiment two: } 24.6 \text { to } 26 \\
\left({ }^{\circ} \mathrm{C}\right)\end{array}$ \\
\hline Trial number & Experimental trial number & Experiment one: 1 to 59 , experiment two: 1 to 51 \\
\hline
\end{tabular}

5-min time windows ( $0-300 \mathrm{~s}, 300-600 \mathrm{~s}$ and $600-900$ s). Thus, in both experiments, the effect of intruder length (TL) was analysed separately for each time window using a strata argument in the model formula (method outlined by Zhang et al., 2018). Commands 'ggcoxdiagnostics' and 'ggcoxfunctional' in the package 'survminer' were used to test for influential observations and non-linearity (Kassambara et al., 2019), and the assumptions were satisfied for both experiments. Packages 'survival' and 'survminer' were used to visualise the results.

The number of agonistic interactions initiated by each fish was analysed using Generalised Linear
Mixed Models (GLMMs in the ' glmmadmb' package) with a negative binomial family (Skaug et al., 2016) for each experiment separately. In each of these models, trial number was included as a random effect to account for the non-independence of data from the two fish tested in the same trial. Models with and without correction for zero-inflation were compared using AICc (Akaike Information Criterion corrected (AICc) for small sample sizes) and the results showed that models not corrected for zero-inflation were more likely. The time spent outside of shelter by the occupant was analysed for both experiments using negative binomial Generalised Linear Models 
(' $g \operatorname{lm} . n b$ ') in the package 'MASS' (Vernables \& Ripley, 2002).

For the number of agonistic interactions, and the time spent in the open by the occupant, five to seven models were constructed based on a priori hypotheses, each containing different combinations of seven explanatory variables and interaction terms. These models were compared using the AICc to indicate the strength of support for each model. Water temperature in the experimental tanks and size difference between intruder and occupant were included as fixed effects because relatively small variations in temperature (Cerqueira et al., 2016) and size difference (Sanches et al., 2012) have been shown to affect the behaviour of $O$. niloticus. The treatment $\times$ size difference and treatment $\times$ temperature interaction terms were included because we hypothesised that size differences and temperature may affect the two species differently. For the analysis of the number of agonistic interactions, role was included as a fixed effect as we predicted that occupants and intruders may differ in their aggression levels. This difference in aggression level between intruders and occupants provided a measure of dominance by measuring the number of agonistic interactions initiated by occupants relative to that of intruders. The inclusion of a treatment $\times$ role interaction term tested whether the degree of dominance shown by the occupant differed between the three treatments. Temperature and absolute size difference were standardised in this analysis using the scale function to improve model convergence.

\section{Results}

Latency for intruder to interact with occupantexperiment one

The probability of an agonistic interaction was lower in the $O$. amphimelas $-O$. amphimelas treatment than in the O. amphimelas-O. niloticus and O. niloticus-O. niloticus treatments, with these latter two treatments not differing significantly from each other (Fig. 2a). Therefore, $O$. amphimelas were more likely to be involved in aggression when the intruder was an $O$. niloticus rather than a conspecific (comparison: coef $=$ $-2.3, \exp ($ coef $)=0.099$, lower $95 \% \mathrm{CI}=0.037$, upper $95 \% \mathrm{CI}=0.267, P<0.001) . O$. niloticus intruders engaged in agonistic interactions in $91 \%$ of trials, and the probability of an interaction occurring did not depend on the occupant species (comparison: $\operatorname{coef}=-$ 0.47 , $\exp ($ coef $)=0.61$, lower $95 \% \mathrm{CI}=0.29$, upper $95 \% \mathrm{CI}=1.33, P=0.22$ ). Warmer temperature was associated with an increased probability of first

Table 3 Model comparison for the negative binomial generalised linear mixed models used to analyse the number of agonistic interactions in experiment one and two

\begin{tabular}{|c|c|c|c|c|c|c|}
\hline Experiment & Model & Explanatory variables & $\mathrm{AICc}$ & $\triangle \mathrm{AICc}$ & $\mathrm{df}$ & Akaike weight \\
\hline \multirow[t]{7}{*}{ One } & $\mathrm{m} 1.2$ & Treatment $\times$ role + absolute size difference + temp & 616.2 & 0 & 10 & 0.83 \\
\hline & m1.1 & Treatment $\times$ role + treatment $\times$ absolute size difference + Temp & 620.8 & 4.7 & 12 & 0.08 \\
\hline & $\mathrm{m} 1.4$ & Treatment + role + absolute size difference + temp & 621.2 & 5 & 8 & 0.07 \\
\hline & $\mathrm{m} 1.5$ & Treatment + absolute size difference + temp & 624.5 & 8.3 & 7 & 0.01 \\
\hline & $\mathrm{m} 1.3$ & Role + treatment $\times$ absolute size difference + temp & 625.6 & 9.4 & 10 & 0.01 \\
\hline & m1.6 & Role + absolute size difference + temp & 648.6 & 32.4 & 6 & 0 \\
\hline & $\mathrm{m} 1.7$ & Absolute size difference + temp & 653.9 & 37.7 & 5 & 0 \\
\hline \multirow[t]{7}{*}{ Two } & $\mathrm{m} 2.2$ & Treatment $\times$ role + absolute size difference + temp & 464.4 & 0 & 10 & 0.76 \\
\hline & $\mathrm{m} 2.1$ & Treatment $\times$ Role + Treatment $\times$ Absolute size difference + temp & 466.7 & 2.3 & 12 & 0.24 \\
\hline & $\mathrm{m} 2.3$ & Role + treatment $\times$ absolute size difference + temp & 492.8 & 28.4 & 10 & 0 \\
\hline & $\mathrm{m} 2.5$ & Treatment + absolute size difference + temp & 499.6 & 35.2 & 7 & 0 \\
\hline & $\mathrm{m} 2.4$ & Treatment + role + absolute size difference + temp & 499.8 & 35.4 & 8 & 0 \\
\hline & $\mathrm{m} 2.6$ & Role + absolute size difference + temp & 520.8 & 56.4 & 6 & 0 \\
\hline & $\mathrm{m} 2.7$ & Absolute size difference + temp & 522.5 & 58.2 & 5 & 0 \\
\hline
\end{tabular}

The random factor was trial number. Temp refers to water temperature 
Table 4 Model comparison for the five negative binomial generalised linear models used to analyse the time spent in the open by the occupant in experiment one and two

\begin{tabular}{|c|c|c|c|c|c|c|}
\hline Experiment & Model & Explanatory variables & AICc & $\Delta \mathrm{AICc}$ & df & Akaike weight \\
\hline \multirow[t]{5}{*}{ One } & $\mathrm{m} 3.5$ & Size difference + temp & 55.6 & 0 & 4 & 0.9 \\
\hline & $\mathrm{m} 3.4$ & Treatment + size difference + temp & 60.4 & 4.8 & 6 & 0.08 \\
\hline & $\mathrm{m} 3.3$ & Treatment $\times$ temp + size difference & 65.3 & 9.7 & 8 & 0.01 \\
\hline & $\mathrm{m} 3.2$ & Treatment $\times$ size difference + temp & 65.5 & 9.9 & 8 & 0.01 \\
\hline & $\mathrm{m} 3.1$ & Treatment $\times$ size difference + treatment $\times$ temp & 70.9 & 15.3 & 10 & 0 \\
\hline \multirow[t]{5}{*}{ Two } & $\mathrm{m} 4.5$ & Size difference + temp & 63.9 & 0 & 4 & 0.85 \\
\hline & $\mathrm{m} 4.4$ & Treatment + size difference + temp & 67.7 & 3.8 & 6 & 0.13 \\
\hline & $\mathrm{m} 4.3$ & Treatment $\times$ temp + size difference & 72.8 & 8.8 & 8 & 0.01 \\
\hline & $\mathrm{m} 4.2$ & Treatment $\times$ size difference + temp & 73.1 & 9.2 & 8 & 0.01 \\
\hline & $\mathrm{m} 4.1$ & Treatment $\times$ size difference + treatment $\times$ temp & 78.7 & 14.8 & 10 & 0 \\
\hline
\end{tabular}
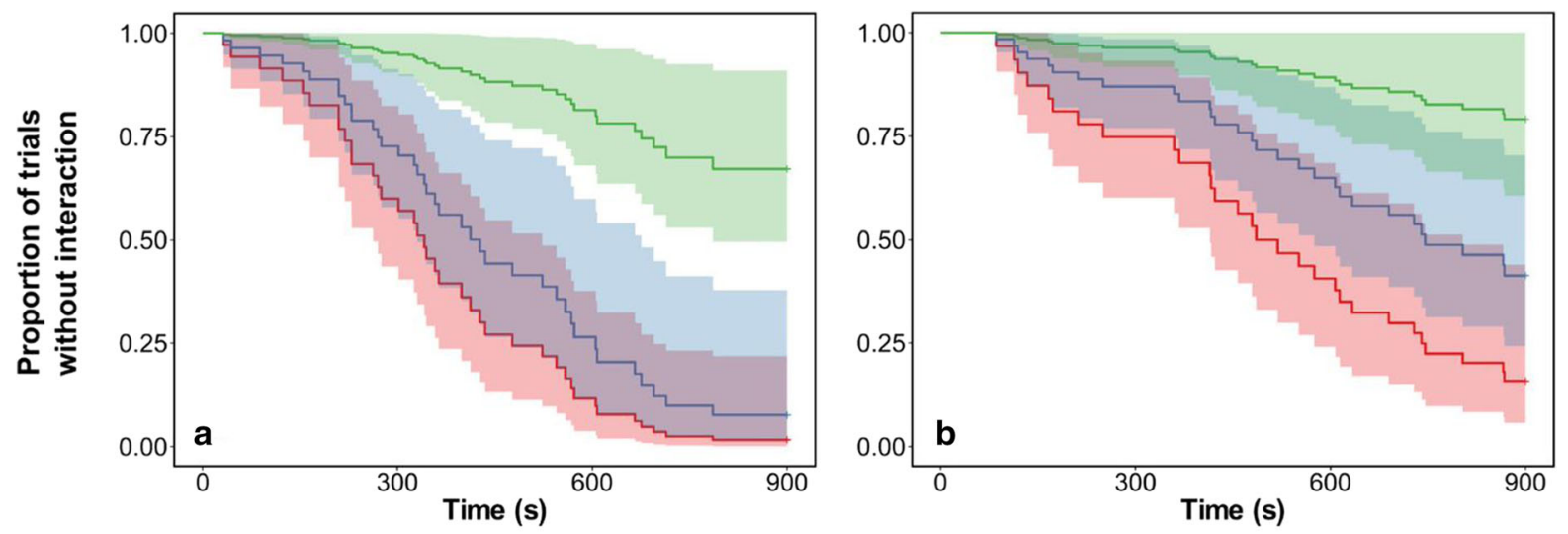

Treatment: $\neq$ O.niloticus $(\mathbf{O})-$ O.niloticus $(\mathbf{I})+0$. amphimelas $(\mathbf{O})-$ O.niloticus $(\mathrm{I})+$ O.amphimelas $(\mathbf{O})-$ O.amphimelas $(\mathrm{I})$

Fig. 2 Latency to first interact $(\mathrm{s} \pm 95 \mathrm{CI})$ in a experiment one and $\mathbf{b}$ experiment two. Each line represents one of the three experimental treatments. Colours represent treatments as

interaction $(\operatorname{coef}=0.81, \exp ($ coef $)=2.27$, lower $95 \%$ $\mathrm{CI}=1.35$, upper $95 \% \mathrm{CI}=3.82, P=0.002$ ). The effect of intruder length (TL) was not consistent over time. In the first time period (0-300 s), larger intruders were more likely to interact $(\operatorname{coef}=0.15$, $\exp (\operatorname{coef})=1.16$, lower $95 \% \mathrm{CI}=1.01$, upper $95 \% \mathrm{CI}=1.34, P=0.03$ ), in the second (300-600 s) there was no significant relationship between intruder length (TL) and the probability of an interaction (coef $=-0.06, \exp$ (coef) $=0.94$, lower $95 \% \mathrm{CI}=0.83$, upper $95 \% \mathrm{CI}=1.06, P=$ $0.33)$, and in the third (600-900 s), larger intruders had a reduced chance of first interaction (coef $=-0.3$, $\exp ($ coef $)=0.74$, lower $95 \% \mathrm{CI}=0.57$, upper $95 \% \mathrm{CI}=$ $0.96, P=0.02)$. The overall model fit was highly indicated by the figure legend, $(\mathrm{O})$ represents the occupant and (I) the intruder in each treatment

significant (Likelihood ratio test $=47.83$, d.f $=6, P<$ 0.001, $n=114$, events $=38$ ).

Latency for intruder to interact with occupant experiment two

When shelters were separated in experiment two, the probability of an agonistic interaction differed significantly between all treatments (Fig. 2b). O. amphimelas-O. amphimelas still had the lowest probability of an interaction and again, $O$. amphimelas occupants were significantly more likely to be involved in aggression when the intruder was an $O$. niloticus rather than a conspecific (comparison: coef $=-1.64$, 
$\exp ($ coef $)=0.19$, lower $95 \% \mathrm{CI}=0.05$, upper $95 \% \mathrm{CI}$ $=0.76, P=0.018)$. $O$. niloticus intruders engaged in agonistic interactions in $70.3 \%$ of trials, a lower proportion than experiment one, and the latency depended significantly on the occupant species with aggression being more likely to occur when paired with a conspecific rather than an $O$. amphimelas (comparison: coef $=-0.92$, $\exp ($ coef $)=0.40$, lower $95 \% \mathrm{CI}=0.16$, upper $95 \% \mathrm{CI}=0.97, P=0.043$ ). The effect of intruder length (TL) had no significant effect on the likelihood of interaction at any of the three time periods (0-300 s, 0-600 s, and $600900 \mathrm{~s})$. Warmer temperature had no significant effect on the likelihood of first interaction. The overall model fit was significant (Likelihood ratio test $=21.18$, d.f $=6, P=0.02$, $n=123$, events $=29$ ).

Number of agonistic interactions-experiment one

Biting was the most common agonistic interaction, followed by chasing (Fig. 3). Mouth fighting was more prevalent than chasing in the $O$. niloticus $-O$. niloticus treatment but was scarce in the other treatments (Fig. 3). The AICc values and Akaike weights indicated $83 \%$ support for the model

Interaction type: $\square$ Biting $\square$ Chasing $\square$ Mouth fighting

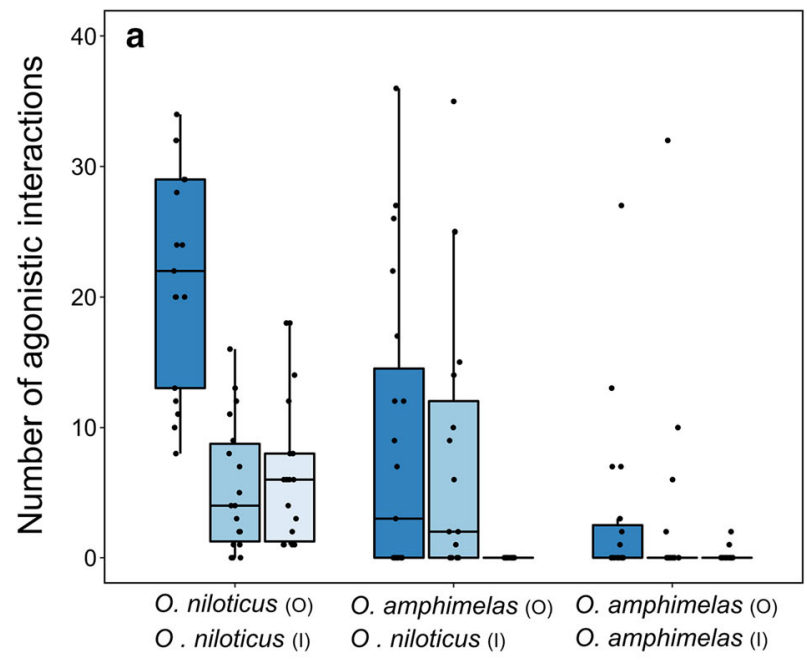

Treatment

Fig. 3 Number of the three types of agonistic interaction in each treatment in a experiment one and $\mathbf{b}$ experiment two. The roles of occupant and intruder are represented in each treatment by $(\mathrm{O})$ and $(\mathrm{I})$ respectively. The distance between the top and bottom of each box represents interquartile range, whiskers containing the treatment and role (intruder or occupant) interaction term, in addition to the main effects contained in all models (Table 3 ). The strong preference for this model suggests that the difference in aggression by occupants and intruders, a measure of dominance, varied between the treatments. Pairwise comparisons revealed that occupants initiated significantly lower numbers of agonistic interactions relative to intruders in the $O$. amphimelas $-O$. niloticus treatment than in the $O$. niloticus $-O$. niloticus (estimate $=-1.32, \mathrm{SE}=0.58, z$ value $=-2.27, \mathrm{P}=0.023$ ) and $O$. amphimelas $-O$. amphimelas (estimate $=-$ $2.48, \mathrm{SE}=0.8, z$ value $=-3.12, \mathrm{P}=0.002$ ) treatments. Thus, dominance was skewed towards $O$. niloticus in the $O$. amphimelas $-O$. niloticus treatment, but was significantly more balanced in the conspecific treatments (Fig. 4a). The O. amphimelas-O. amphimelas treatment had the lowest levels of aggression, with cases of aggression only occurring in $37 \%$ of trials (Fig. 4a).

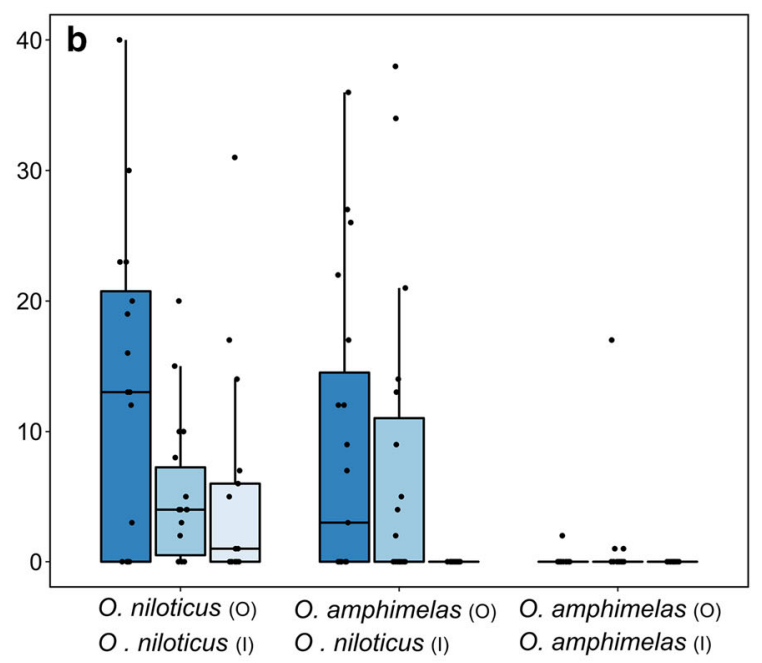

Treatment

extend to data points within 1.5 times the interquartile range, and the line through the centre of each box represents the median. Individual data points are scattered over their corresponding treatment with added jitter for clarity, and those above or below the whiskers represent outliers 


\section{Agonistic interactions initiated by: $\square$ Occupant}

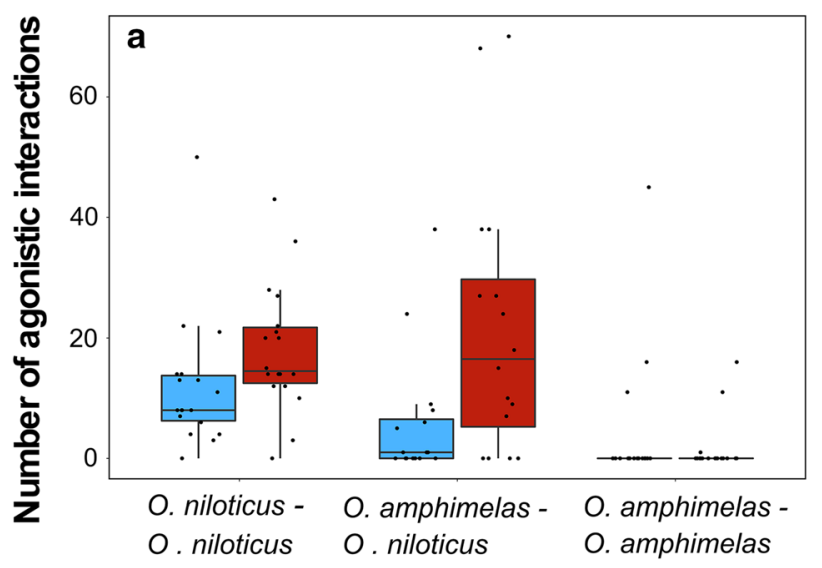

Treatment

Fig. 4 Agonistic interactions initiated by the intruder and the occupant across the three treatments in a experiment one and b experiment two. The distance between the top and bottom of each box represents interquartile range, whiskers extend to data points within 1.5 times the interquartile range, and the line

Number of agonistic interactions-experiment two

The AICc values and Akaike weights indicate $76 \%$ support for the model containing the treatment and role interaction term, in addition to the main effects contained in all models (Table 3). This strong preference for this model suggests that the difference in dominance between intruders and occupants differed significantly between treatments. Similarly to experiment one, pairwise comparisons reveal that the number of agonistic interactions initiated by occupants relative to intruders was significantly lower in the O. amphimelas-O. niloticus treatment than in the O. niloticus $-O$. niloticus (estimate $=-3.61, \mathrm{SE}=$ $0.53, z$ value $=-6.79, P<0.001)$ and $O$. amphimelas $O$. amphimelas (estimate $=-6.58, \mathrm{SE}=1.32, z$ value $=-5, P<0.001)$ treatments. Therefore, balanced dominance levels were observed between conspecifics, but in the $O$. amphimelas-O. niloticus treatment, $O$. niloticus showed significant competitive dominance (Fig. 4b).
Intruder

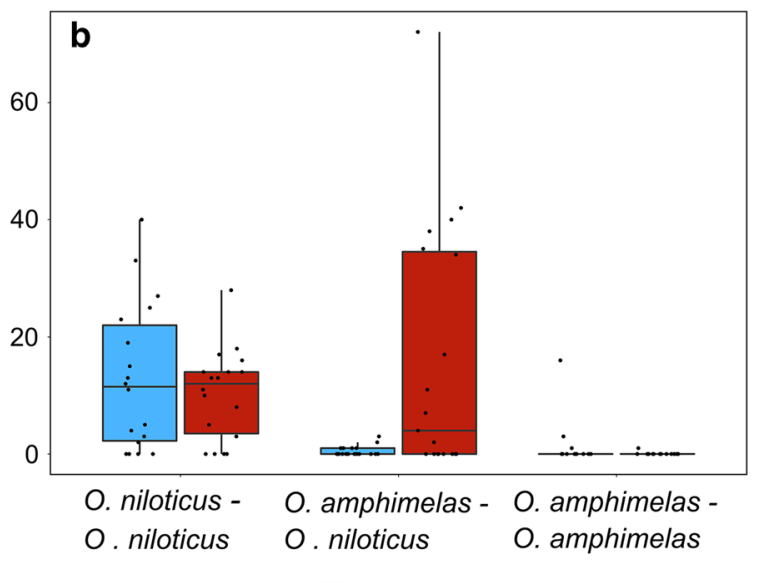

Treatment

through the centre of each box represents the median. Individual data points are scattered over their corresponding treatment with added jitter for clarity, and those above or below the whiskers represent outliers

Time spent out of shelter by the occupantexperiment one and two

The AICc values and Akaike weights indicate $90 \%$ support in experiment one and $85 \%$ support in experiment two for the simplest model that lacked the treatment variable (Table 4). This suggests that in both experiments the time spent out of shelter by the occupant did not vary considerably between treatments (Fig. 5), and the effects of temperature and size difference were not treatment specific as the models with interaction terms were not well supported by the data.

\section{Discussion}

In both experiments, when $O$. amphimelas individuals were paired with an $O$. niloticus, agonistic interactions were initiated more quickly and were more frequent across the trial than when $O$. amphimelas were paired with a conspecific. Thus, $O$. niloticus dominated competitive interactions with $O$. amphimelas, while in the conspecific pairings, dominance between occupants and intruders was significantly more balanced. Differences in competitive ability between the two species appears to drive dominance of $O$. niloticus 


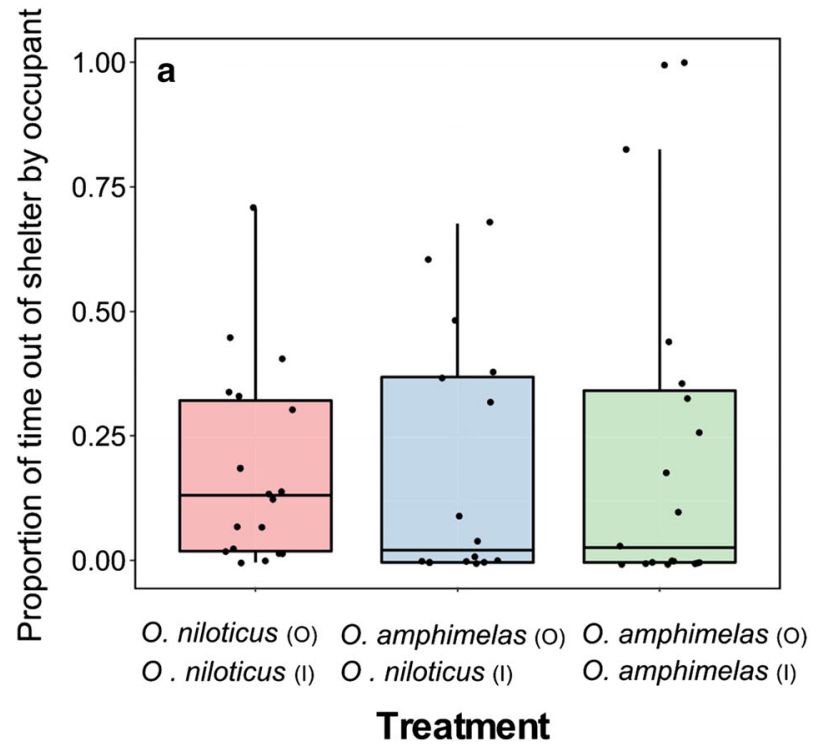

Fig. 5 Time spent out of the shelter by the occupant across the three treatments in $\mathbf{a}$ experiment one and $\mathbf{b}$ experiment two. The roles of occupant and intruder are represented in each treatment by $(\mathrm{O})$ and (I) respectively. The distance between the top and bottom of each box represents interquartile range, whiskers

over O. amphimelas, rather than the roles of intruder or occupant. Providing two spatially separated shelters appeared to reduce the likelihood of an interaction occurring across all treatments, although $O$. niloticus still showed competitive dominance over $O$. amphimelas. Thus, it appears that the probability of competition occurring may be reduced through resource partitioning; however, when competition does occur, $O$. niloticus will dominate competitive encounters with O. amphimelas.

The competitive dominance of $O$. niloticus demonstrated here presents a mechanism through which invasive $O$. niloticus could negatively affect native species in the biodiverse freshwater systems of East Africa. The outcome of interspecific competition can fundamentally change the resource use of individuals, which can drive habitat displacement at the population level (Morse, 1974; Nakano, 1995). Displacement from preferred habitat by invasive species has been linked to superiority in competitive interactions over food (Petren \& Case, 1996), space (Carlton et al., 1999) and shelter (Case et al., 1994; Mooney \& Cleland, 2001), and has caused declines in the diversity and abundance of native species (Porter \& Savignano, 1990). When combined with strong niche overlap, competitive dominance by $O$. niloticus could

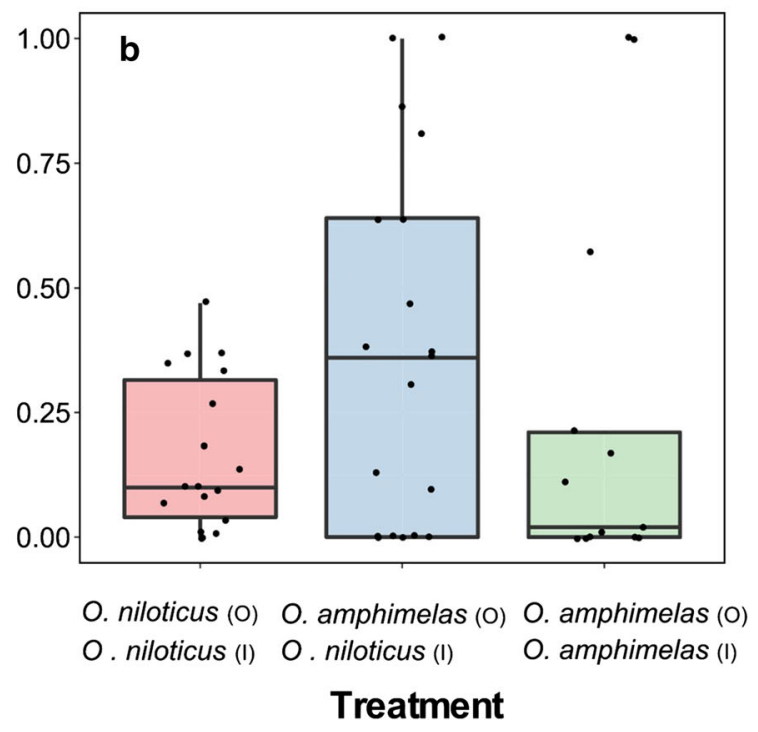

extend to data points within 1.5 times the interquartile range, and the line through the centre of each box represents the median. Individual data points are scattered over their corresponding treatment with added jitter for clarity, and those above or below the whiskers represent outliers

result in similar effects under field conditions and discourage native species from accessing resources. If interspecific competition is found to occur over shelter, the ecological consequences for displacement are likely to be strong due to an increase in predation (Martin et al., 2010), a key driver for population reduction and in some cases, extinction (Blackburn et al., 2004; Sax \& Gaines, 2008). We therefore recommend that field surveys investigating the habitat use of $O$. niloticus and $O$. amphimelas are undertaken, as accurate predictions on the likelihood of ecological consequences require habitat use data.

In neither experiment did we find any difference in the time spent out of shelter by the occupant between treatments. Laboratory studies on a variety of fish species have reported habitat displacement as a result of interference competition (Mills et al., 2004; Martin et al., 2010; Grabowska et al., 2016). Therefore, it is particularly surprising that $O$. amphimelas occupants did not spend more time out of shelter when paired with $O$. niloticus compared to when they were paired with another $O$. amphimelas, since they received much more aggression when paired with $O$. niloticus. It is likely that the 15-min recording period, and lack of alternative habitats, may not have been sufficient to capture longer-term behavioural outcomes of the 
competitive interactions such as changes in habitat use (Morse, 1974). With a longer trial length where alternative habitats were available and competition could be evaded by moving to a different habitat, we predict that $O$. amphimelas would be displaced from its preferred habitat under laboratory conditions to avoid competition with dominant $O$. niloticus. In addition, shelter use is known to consistently vary between individuals within populations (Ioannou \& Dall, 2016), and individuals can also vary in how they change their shelter use when other individuals are present (Bevan et al., 2018). This inter-individual variation would have contributed to within-treatment variation in our experiments, possibly concealing any effect between treatments.

Mean size differences between occupants and intruders were below $3 \%$ in both experiments, and never exceeded $10 \%$ in any individual trial (Table 1). In situ, however, O. niloticus have especially high growth rates, and typically reach considerably larger sizes than $O$. amphimelas and other sympatric tilapia species (Froese \& Pauly, 2019). The maximum standard lengths reported for $O$. niloticus and $O$. amphimelas are $60 \mathrm{~cm}$ and $28 \mathrm{~cm}$ respectively (Froese $\&$ Pauly, 2019). The advantage of increased body-size in competitive interactions is well established in fish (Francis, 1983; Abbott et al., 1985) and thus the dominance shown by $O$. niloticus in this experiment could be heightened in situ. Consequently, the results from this experiment may represent a near best-case scenario, where competitive interactions between $O$. niloticus and native Tanzanian species occur at equal body-sizes. While small body-size differences can be overridden by differences in other competitive traits such as aggression (Hasegawa et al., 2004), this is unlikely to benefit $O$. amphimelas, which we found to be considerably less aggressive than $O$. niloticus.

If prolonged, one-sided dominance hierarchies such as the one observed in this experiment can result in the monopolisation of resources in favour of the dominant individual or species (Harwood et al., 2003). For example, under laboratory conditions, $O$. niloticus can prevent subordinate conspecifics from accessing food patches (Barreto et al., 2006). Mesocosm experiments revealed that $O$. niloticus can reduce the growth rate of native species with a similar diet when they are cultured alongside one another (Gu et al., 2015), highlighting the potential for a positive feedback loop between growth rate and competitive dominance. In such a mechanism, the effects of dominance could reduce access to resources, slowing growth rate, heightening size differences between species and increasing dominance by $O$. niloticus in future interactions. The tendency for tilapia to move from shallow shelter areas to open water as their body-size increases may present one mitigating factor by reducing competition over shelter when body-size discrepancies become more apparent (Lowe-McConnell, 2000). However, further evidence describing the extent of resource overlap between $O$. niloticus and native species at different body-sizes and in different habitat types is imperative to make more detailed predictions regarding the outcomes of competitive dominance by O. niloticus.

Here we show that $O$. niloticus dominate competitive encounters with $O$. amphimelas, providing the first experimental evidence that competition with $O$. niloticus may result in harmful consequences for native tilapia species, as has been theorised (Goudswaard et al., 2002; Canonico et al., 2005). Behavioural studies such as this one can provide direct evidence for mechanisms which may underpin negative effects of $O$. niloticus on native species. Such evidence is highly important to design effective management strategies, allocate resources, and implement policy decisions surrounding $O$. niloticus invasions. Ideally, these investigations would be undertaken in situ; however, this is often not feasible due to limitations in visibility, especially in turbid or vegetated areas. As a result, laboratory experiments must be designed to most closely and accurately replicate natural conditions, and to preserve the relevant behaviours of experimental subjects. With this in mind, the interpretation of results from this study could benefit from two key areas of research. Firstly, field survey data on the resource use of $O$. niloticus and native tilapia would improve the accuracy of predictions about the implications of the behavioural mechanisms demonstrated here. Secondly, studying the behaviour of $O$. niloticus and $O$. amphimelas in situ or with wild caught individuals could help to compare the differences between captive and wild phenotypes, and serve to verify the use of laboratory-reared individuals in studies of invasive species. Given the results of our experiment, the potential severity of competitive dominance by invasive species, and the threatened status of many indigenous tilapia, future research in these two areas, in conjunction with laboratory 
experiments, could form an important component in limiting the harmful effects of $O$. niloticus across its non-native range.

Acknowledgements We are grateful to Professor George Turner for providing the $O$. amphimelas used in this study and to Alex Bartlett for assisting in the collection of the O. niloticus subjects. This project was funded by a NERC GW4+ FRESH CDT PhD studentship awarded to TC (NE/R011524/1) and we are thankful to the GW4 FRESH Centre for Doctoral Training in Freshwater Biosciences and Sustainability for their support of this project.

Open Access This article is licensed under a Creative Commons Attribution 4.0 International License, which permits use, sharing, adaptation, distribution and reproduction in any medium or format, as long as you give appropriate credit to the original author(s) and the source, provide a link to the Creative Commons licence, and indicate if changes were made. The images or other third party material in this article are included in the article's Creative Commons licence, unless indicated otherwise in a credit line to the material. If material is not included in the article's Creative Commons licence and your intended use is not permitted by statutory regulation or exceeds the permitted use, you will need to obtain permission directly from the copyright holder. To view a copy of this licence, visit http://creativecommons.org/licenses/by/4.0/.

\section{References}

Abbott, J., R. Dunbrack \& C. Orr, 1985. The interaction of size and experience in dominance relationships of juvenile steelhead trout (Salmo gairdneri). Behaviour 92: 241-253.

Al Hafedh, Y. S., A. Q. Siddiqui \& M. Y. Al-Saiady, 1999. Effects of dietary protein levels on gonad maturation, size and age at first maturity, fecundity and growth of Nile tilapia. Aquaculture International 7: 319-332.

Alvarenga, C. M. D. \& G. L. Volpato, 1995. Agonistic profile and metabolism in alevins of the Nile tilapia. Physiology \& Behavior 57: 75-80.

Avella, M., J. Berhaut \& M. Bornancin, 1993. Salinity tolerance of two tropical fishes, Oreochromis aureus and O. niloticus. I. Biochemical and morphological changes in the gill epithelium. Journal of Fish Biology 42: 243-254.

Bailey, J., A. Alanäuräu \& E. Bräunnäus, 2000. Methods for assessing social status in Arctic charr. Journal of Fish Biology 57: 258-261.

Balirwa, J. S., C. A. Chapman, L. J. Chapman, I. G. Cowx, K. Geheb, L. Kaufman, R. H. Lowe-McConnell, O. Seehausen, L. H. Wannik \& R. L. Welcomme, 2003. Biodiversity and fishery sustainability in the Lake Victoria basin: an unexpected marriage? AIBS Bulletin 53: 703-715.

Barreto, R. E., P. Rodrigues, A. C. Luchiarai \& H. C. Delicio, 2006. Time-place learning in individually reared angelfish, but not in pearl cichlid. Behavioural Processes 73: 367-372.
Bayona, J. D. R. 2006. Oreochromis amphimelas. The IUCN Red List of Threatened Species 2006: e.T60629A12388607. http://dx.doi.org/10.2305/IUCN. UK.2006.RLTS.T60629A12388607.en. Downloaded on 09 September 2019.

Bevan, P. A., I. Gosetto, E. R. Jenkins, I. Barnes \& C. C. Ioannou, 2018. Regulation between personality traits: individual social tendencies modulate whether boldness and leadership are correlated. Proceedings of the Royal Society B: Biological Sciences 285: 20180829.

Blackburn, T. M., P. Cassey, R. P. Duncan, K. L. Evans \& K. J. Gaston, 2004. Avian extinction and mammalian introductions on oceanic islands. Science 305: 1955-1958.

Bradbeer, S. J., J. Harrington, H. Watson, A. Warraich, A. Shechonge, A. Smith, R. Tamatamah, B. P. Ngatunga, G. F. Turner \& M. J. Genner, 2019. Limited hybridization between introduced and critically endangered indigenous tilapia fishes in northern Tanzania. Hydrobiologia 832: 257-268.

Canonico, G. C., A. Arthington, J. K. McCrary \& M. L. Thieme, 2005. The effects of introduced tilapias on native biodiversity. Aquatic Conservation: Marine and Freshwater Ecosystems 15: 463-483.

Carlton, J. T., J. B. Geller, M. L. Reaka-Kudla \& E. A. Norse, 1999. Historical extinctions in the sea. Annual Review of Ecology and Systematics 30: 515-538.

Case, T. J., D. T. Bolger \& K. Petren, 1994. Invasions and competitive displacement among house geckos in the tropical Pacific. Ecology 75: 464-477.

Cerqueira, M., S. Rey, T. Silva, Z. Featherstone, M. Crumlish \& S. Mackenzie, 2016. Thermal preference predicts animal personality in Nile tilapia Oreochromis niloticus. Journal of Animal Ecology 85: 1389-1400.

Champneys, T., G. Castaldo, S. Consuegra \& C. Garcia de Leaniz, 2018. Density-dependent changes in neophobia and stress-coping styles in the world's oldest farmed fish. Royal Society Open Science 5: 181473.

Costa-Pierce, B. A., 2003. Rapid evolution of an established feral tilapia (Oreochromis spp.): the need to incorporate invasion science into regulatory structures. Biological Invasions 5: 71-84.

Donnelly, B., 1969. A preliminary survey of Tilapia nurseries on Lake Kariba during 1967/68. Hydrobiologia 34: 195-206.

Ehrlich, P., 1989. Attributes of invaders and the invading processes vertebrates. In Drake, J. A., H. A. Mooney, F. DiCastri, R. H. Groves, F. J. Kruger, M. Rejmánek \& M. Williamson (eds), Biological Invasions: a Global Perspective. Wiley, New York: 315-328.

Enquist, M., O. Leimar, T. Ljungberg, Y. Mallner \& N. Segerdahl, 1990. A test of the sequential assessment game: fighting in the cichlid fish Nannacara anomala. Animal Behaviour 40: 1-14.

FAO, 2018. The State of World Fisheries and Aquaculture 2018. Meeting the sustainable development goals, FAO, Rome.

Francis, R. C., 1983. Experiential effects on agonistic behavior in the paradise fish, Macropodus opercularis. Behaviour 85: 292-313.

Friard, O. \& M. Gamba, 2016. BORIS: a free, versatile opensource event-logging software for video/audio coding and live observations. Methods in Ecology and Evolution 7: 1325-1330. 
Froese, R. \& D. Pauly (eds). 2019. FishBase. World Wide Web electronic publication. www.fishbase.org, (04/2019).

Goudswaard, P., F. Witte \& E. Katunzi, 2002. The tilapiine fish stock of Lake Victoria before and after the Nile perch upsurge. Journal of Fish Biology 60: 838-856.

Grabowska, J., T. Kakareko, D. Błońska, M. Przybylski, J. Kobak \& G. Copp, 2016. Interspecific competition for a shelter between non-native racer goby and native European bullhead under experimental conditions - effects of season, fish size and light conditions. Limnologica 56: 30-38.

Gu, D. E., G. M. Ma, Y. J. Zhu, M. Xu, D. Luo, Y. Y. Li, H. Wei, X. D. Mu, J. R. Luo \& Y. C. Hu, 2015. The impacts of invasive Nile tilapia (Oreochromis niloticus) on the fisheries in the main rivers of Guangdong Province, China. Biochemical Systematics and Ecology 59: 1-7.

Harwood, A. J., J. D. Armstorng, N. B. Metcalfe \& S. W. Griffiths, 2003. Does dominance status correlate with growth in wild stream-dwelling Atlantic salmon (Salmo salar)? Behavioral Ecology 14: 902-908.

Hasegawa, K., T. Yamamoto, M. Murakami \& K. Maekawa, 2004. Comparison of competitive ability between native and introduced salmonids: evidence from pairwise contests. Ichthyological Research 51: 191-194.

Ioannou, C. C. \& S. R. X. Dall, 2016. Individuals that are consistent in risk-taking benefit during collective foraging. Scientific Reports 6: 1-9.

Kassambara, A., M. Kosinski \& P. Biecek, 2019. survminer: Drawing Survival Curves using'ggplot2'. R package version 0.4.5. https://CRAN.R-project.org/package= survminer.

Kaufman, L., 1992. Catastrophic change in species-rich freshwater ecosystems. BioScience 42: 846-858.

Kulhanek, S. A., A. Ricciardi \& B. Leung, 2011. Is invasion history a useful tool for predicting the impacts of the world's worst aquatic invasive species? Ecological Applications 21: 189-202.

Lowe-McConnell, R., 2000. The roles of tilapias in ecosystems. Biology and Exploitation. Springer, Tilapias.

Lévêque, C., 1997. Biodiversity dynamics and conservation: the freshwater fish of tropical Africa. Cambridge University Press, Cambridge.

Martin, C. W., M. M. Valentine \& J. F. Valentine, 2010. Competitive interactions between invasive Nile tilapia and native fish: the potential for altered trophic exchange and modification of food webs. PLoS ONE 5: e14395.

McCrary, J., E. Van Den Berghe, K. McKaye \& L. Lopez Perez, 2001. Tilapia cultivation: a threat to native fish species in Nicaragua. Encuentro 58: 9-19.

Mills, M. D., R. B. Rader \& M. C. Belk, 2004. Complex interactions between native and invasive fish: the simultaneous effects of multiple negative interactions. Oecologia 141: 713-721.

Mooney, H. A. \& E. E. Cleland, 2001. The evolutionary impact of invasive species. Proceedings of the National Academy of Sciences of the USA 98: 5446-5451.

Moralee, R., F. Van Der Bank \& B. Van Der Waal, 2000. Biochemical genetic markers to identify hybrids between the endemic Oreochromis mossambicus and the alien species, O. niloticus (Pisces: Cichlidae). Water SA 26: 263-268.
Morse, D. H., 1974. Niche breadth as a function of social dominance. The American Naturalist 108: 818-830.

Nakano, S., 1995. Competitive interactions for foraging microhabitats in a size-structured interspecific dominance hierarchy of two sympatric stream salmonids in a natural habitat. Canadian Journal of Zoology 73: 1845-1854.

Naylor, R. L., S. L. Williams \& D. R. Strong, 2001. Aquaculture - a gateway for exotic species. Science 294: 1655-1656.

Njiru, M., J. Okeyo-Owuor, M. Muchiri \& I. Cowx, 2004. Shifts in the food of Nile tilapia, Oreochromis niloticus (L.) in Lake Victoria. Kenya. African Journal of Ecology 42: 163-170.

Ogutu-Ohwayo, R., 1990. The decline of the native fishes of lakes Victoria and Kyoga (East Africa) and the impact of introduced species, especially the Nile perch, Lates niloticus, and the Nile tilapia, Oreochromis niloticus. Environmental Biology of Fishes 27: 81-96.

Oliveira, R. F., A. Silva \& A. V. Canario, 2004. Why do winners keep winning? Androgen mediation of winner but not loser effects in cichlid fish. Proceedings of the Royal Society B: Biological Sciences 276: 2249-2256.

Parker, I. M., D. Simberloff, W. Lonsdale, K. Goodell, M. Wonham, P. M. Kareiva, M. H. Williamson, P. B. Von Holle, P. B. Moyle, J. E. Byers \& L. Goldwasser, 1999. Impact: toward a framework for understanding the ecological effects of invaders. Biological Invasions 1: 3-19.

Petren, K. \& T. J. Case, 1996. An experimental demonstration of exploitation competition in an ongoing invasion. Ecology 77: 118-132.

Porter, S. D. \& D. A. Savignano, 1990. Invasion of polygyne fire ants decimates native ants and disrupts arthropod community. Ecology 71: 2095-2106.

Pringle, R. M., 2005. The origins of the Nile perch in Lake Victoria. BioScience 55: 780-787.

R Core Team. 2019. R: a language and environment for statistical computing. R Foundation for Statistical Computing, Vienna. https://www.R-project.org/.

Sanches, F. H. C., C. A. Miyai, T. M. Costa, R. A. Christofoletti, G. L. Volpato \& R. E. Barreto, 2012. Aggressiveness overcomes body-size effects in fights staged between invasive and native fish species with overlapping niches. PLoS ONE 7: e29746.

Sax, D. F. \& S. D. Gaines, 2008. Species invasions and extinction: the future of native biodiversity on islands. Proceedings of the National Academy of Sciences of the USA 105: 11490-11497.

Shechonge, A., B. P. Ngatunga, S. J. Bradbeer, J. J. Day, J. J. Freer, A. G. Ford, J. Kihedu, T. Richmond, S. Mzighani \& A. M. Smith, 2019. Widespread colonisation of Tanzanian catchments by introduced Oreochromis tilapia fishes: the legacy from decades of deliberate introduction. Hydrobiologia 832: 235-253.

Shelton, W. L. 2002. Tilapia culture in the 21 st century. Tilapia Farming in the 21 st Century, Proc. Int. Forum on Tilapia Farming in the 21st Century, pp. 1-20.

Skaug, H., D. Fournier, B. Bolker, A. Magnusson \& A. Nielsen, 2016. Generalized Linear Mixed Models using 'AD Model Builder'. R package version 0.8.3.3.

Starling, F., X. Lazzaro, C. Cavalcanti \& R. Moreira, 2002. Contribution of omnivorous tilapia to eutrophication of a 
shallow tropical reservoir: evidence from a fish kill. Freshwater Biology 47: 2443-2452.

Therneau, T. 2015. A package for survival analysis in S. version 2.38. https://CRAN.R-project.org/package=survival.

Trewavas, E., 1983. Tilapiine fishes of the genera Sarotherodon, Oreochromis and Danakilia. British Museum (Natural History), London.

Trewavas, E. \& G. Fryer, 1965. Species of Tilapia (Pisces, Cichlidae) in Lake Kitangiri, Tanzania, East Africa. Proceedings of the Zoological Society of London 147: 108-118.

Turner, G. F., 2007. Adaptive radiation of cichlid fish. Current Biology 17: R827-R831.

Turner, G. F., B. P. Ngatunga, \& M. J. Genner, 2019. A survey of fishes of Hombolo Lake, Dodoma, Tanzania, with evidence for local extinction of a native tilapia as a consequence of stocking. BioRxiv 452847.

Uddin, M. N. \& R. W. Robinson, 2017. Responses of plant species diversity and soil physical-chemical-microbial properties to Phragmites australis invasion along a density gradient. Scientific Reports 7: 1-13.

Van Der Waal, B. \& R. Bills, 2000. Oreochromis niloticus (Teleostei: Cichlidae) now in the Limpopo River system. South African Journal of Science 96: 47-48.
Vander Zanden, M. J., J. D. Olden, J. H. Thorne \& N. E. Mandrak, 2004. Predicting occurrences and impacts of smallmouth bass introductions in north temperate lakes. Ecological Applications 14: 132-148.

Vernables, W. N. \& B. D. Ripley, 2002. Modern applied statistics with S, 4th ed. Springer, New York. ISBN 0-38795457-0.

Zale, A. V. \& R. W. Gregory, 1989. Effect of salinity on cold tolerance of juvenile blue tilapias. Transactions of the American Fisheries Society 118: 718-720.

Zengeya, T. A., A. J. Booth \& C. T. Chimimba, 2015. Broad niche overlap between invasive Nile tilapia Oreochromis niloticus and indigenous congenerics in southern Africa: should we be concerned? Entropy 17: 4959-4973.

Zhang, Z., J. Reinikainen, K. A. Adeleke, M. E. Pieterse \& C. G. Groothius-Oudshoorn, 2018. Time-varying covariates and coefficients in Cox regression models. Annals of Translational Medicine 6: 121 .

Publisher's Note Springer Nature remains neutral with regard to jurisdictional claims in published maps and institutional affiliations. 